\title{
The experimental determination of the thermal conductivity of melting chocolate: thermal resistance analogies and free convection boundary conditions
}

\author{
M. M. Dreger \& L. Pitol-Filho \\ Centro Universitário Católica de Santa Catarina, Brazil
}

\begin{abstract}
In the food industry, heat transfer phenomena take place in several steps of chocolate preparation. Therefore, a complete thermal analysis of such process requires an accurate determination of a variety of thermo physical properties, including thermal conductivity. To obtain the thermal conductivity, chocolate $\left(2.0 \mathrm{dm}^{3}\right)$ was stored in a stainless steel rectangular box, provided with a double jacket, with a continuous flow of water at $50^{\circ} \mathrm{C}$. The side walls were insulated, and the opposite wall was exposed to natural convection conditions, by using either stagnant air or melting ice, forcing therefore a heat flux. The thermal conductivity of chocolate was calculated by applying thermal resistances, as soon as the system reached steady state operation. In the experiments where the temperature gradient was established by using melting ice, the results are not reasonable, owing to the latent heat transferred to the water-ice mixture. On the other hand, where air free convection was applied, results were according to the literature, ranging from $0.16 \mathrm{~W} /(\mathrm{m} . \mathrm{K})$ to $0.35 \mathrm{~W} /(\mathrm{m} . \mathrm{K})$, for different fractions of milk and cocoa in the chocolate compositions. Measurements uncertainties are also discussed.
\end{abstract}

Keywords: chocolate compositions, thermal conductivity, free convection, thermal resistances.

\section{Introduction}

Chocolate is a complex suspension in a fat continuous phase [1] whose sensory properties are controlled mainly by the crystal structure and polymorphism of cocoa butter [2], in a variety of successful formulas, produced by an empirical 
management of ingredient combinations [3]. The rheological properties are affected by composition and processing methods [4]. Prior to packaging, chocolate is stored in jacketed tanks [4]. A continuous flow of hot water along the jacket provides the needed amount of heat to avoid chocolate solidification. The proper heat transfer also prevents microbial activity and enzymatic degradation, ensuring to the product the desired taste, colour and texture [5]. One of the most important physical properties involved in such process is thermal conductivity of the melting chocolate, whose behaviour is highly non-Newtonian [6]. Owing to the formulas complexities, the prediction of the thermal conductivity is complicated. The present works reports the results of a unit designed to measure the thermal conductivity of melting chocolate for milk, white and semisweet chocolate formulations. To obtain the thermal conductivity, chocolate was stored in a stainless steel rectangular box, provided with a double jacket, with a continuous flow of water at $50^{\circ} \mathrm{C}$. The side walls were insulated, and the opposite wall was exposed to natural convection conditions, by using either stagnant air or melting ice, forcing therefore a heat flux. By applying thermal resistance analogies the thermal conductivity could be determined.

\section{Materials and methods}

\subsection{Chocolate}

Three kinds of chocolate with different compositions were used in this study to determine whether the thermal conductivity has a significant variation in these formulations. Figure 1 shows the proportion of ingredients used in each formula.

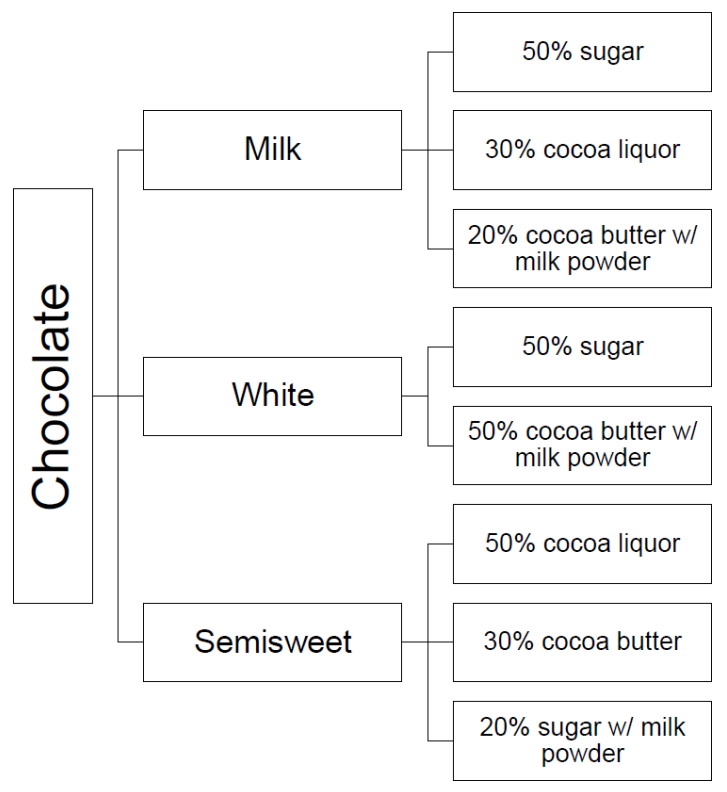

Figure 1: Chocolate formulations flowchart. 
The compositions shown in Figure 1 are popular formulas, with sugar, milk powder, cocoa liquor and cocoa butter in proportions that provide firmness and physical stability to milk, white and semisweet chocolates.

\subsection{Experimental method}

The unit shown in Figure 2 is a closed system. The double jacket of the chocolate container receives hot water from the reservoir equipped with an electrical resistor. Then, the chocolate is heated in one side of the container. Since the opposite side is exposed to ambient temperature, a heat flux is generated through the chocolate container.

An electrical resistor was used to keep the temperature of the water around $52^{\circ} \mathrm{C}$ in the reservoir. Figure 3 shows how the heat flows once the temperature gradient is established.

In Figure 3 it is possible to observe in detail the jacket and the direction of the heat flow. On the left side of the container, the surface is insulated, therefore the heat flows to the right side, where a free convection condition was applied, by exposing the surface either to ambient air or to melting ice. A digital thermometer with four channels was used, allowing two measurement points at the inner surface and two points at the outer surface. All the temperatures were measured inside the chocolate container and an average temperature was calculated for each surface.

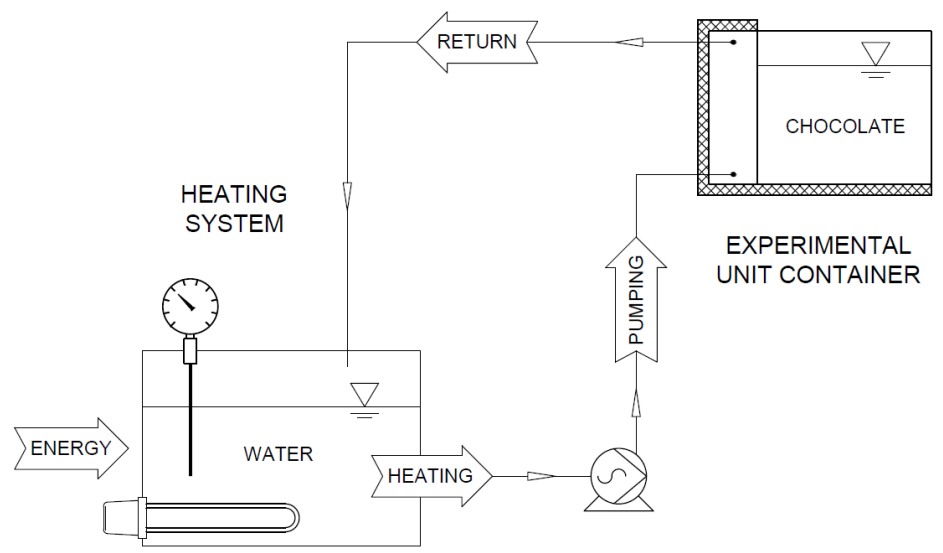

Figure 2: Working flowchart of the experimental unit system.

Three different boundary conditions were applied to the container surface exposed to ambient. For the first condition, a stainless steel box containing melting ice was fixed to the wall, forcing the temperature to $0^{\circ} \mathrm{C}$. For the second condition, the chocolate container was exposed to ambient air at $20^{\circ} \mathrm{C}$. Finally, the air temperature was set to $30^{\circ} \mathrm{C}$, approximately what is used at industrial plants as working ambient temperature. The boundary condition variations were helpful to evaluate the chocolate thermal conductivity at different temperatures. 


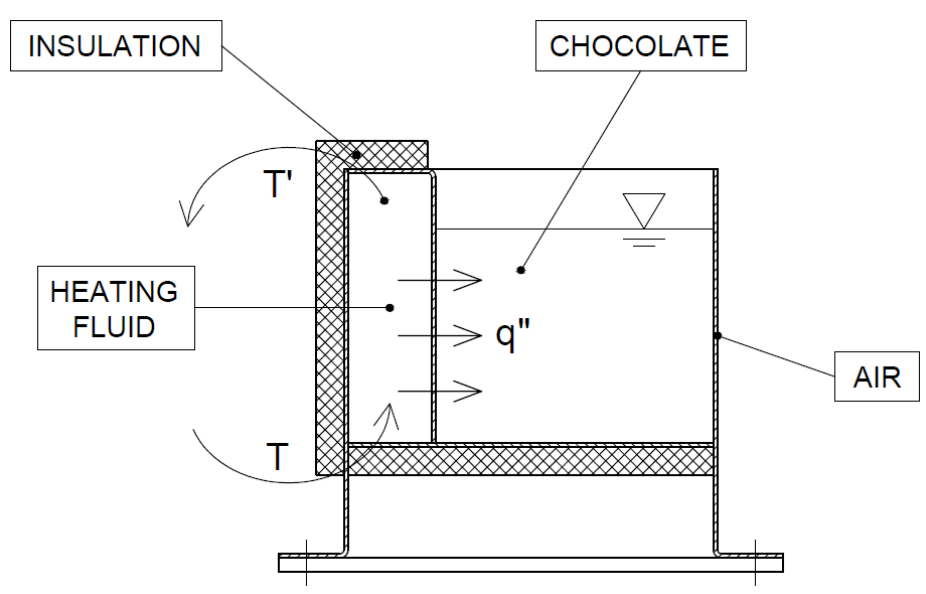

Figure 3: Scheme of heat transfer inside of the experimental container.

\subsection{Thermal resistance analogies}

Two different heat flux mechanisms take place in the chocolate container: conduction through the chocolate and free convection at the wall exposed to the air or to the melting ice [6]. By comparing the two mechanisms, it is possible to determine the thermal conductivity inside of the chocolate by the experimental method proposed. Table 1 shows the thermal properties [6] of the air for two different temperatures.

Table 1: Thermal properties of the ambient air for free convection [6].

\begin{tabular}{lcc}
\hline Temperature & $20^{\circ} \mathrm{C}$ & $30^{\circ} \mathrm{C}$ \\
\hline Specific mass $\left[\mathrm{kg} . \mathrm{m}^{-3}\right]$ & 1.1933 & 1.1509 \\
Specific heat $\left[\mathrm{J} .(\mathrm{kg} . \mathrm{K})^{-1}\right]$ & 1006.8630 & 1007.1260 \\
Thermal conductivity $\left[\mathrm{W} .(\mathrm{m} . \mathrm{K})^{-1}\right]$ & 0.0258 & 0.0265 \\
Dynamic viscosity $[\mathrm{mPa} . \mathrm{s}]$ & 0.0182 & 0.0186 \\
Kinematic viscosity $\left[10^{-5} \mathrm{~m}^{2} \cdot \mathrm{s}^{-1}\right]$ & 1.5252 & 1.6161 \\
Prandtl & 0.7088 & 0.7066 \\
\hline
\end{tabular}

The Grashof (Gr) number (eqn 1) expresses a ratio of the buoyancy to the viscous forces acting in the fluid [6]:

$$
G r=\frac{g \beta\left(T_{e}-T_{\infty}\right) x^{3}}{v^{2}}
$$


where $\mathrm{g}$ is the gravity acceleration $\left(\mathrm{m}^{-\mathrm{s}^{-2}}\right), \beta$ is the volumetric expansion coefficient $\left(\mathrm{K}^{-1}\right)$, Te is the external temperature of chocolate $\left({ }^{\circ} \mathrm{C}\right)$, To is the ambient temperature $\left({ }^{\circ} \mathrm{C}\right)$, $\mathrm{x}$ corresponds to the position on the external surface $(\mathrm{m})$ and, $v$ is the kinematic viscosity $\left(\mathrm{m}^{2} \cdot \mathrm{s}^{-1}\right)$. By applying an appropriate Nusselt correlation $(\mathrm{Nu})$ it is possible to determine the free convection coefficient. For free convection acting on a flat surface, eqn (2) may be used [6]:

$$
N u_{x}=\frac{h_{x} X}{k}=0.508 \operatorname{Pr}^{1 / 2}\left(\frac{G r_{x}}{0.952+P r}\right)^{1 / 4}
$$

where $\mathrm{k}$ is the thermal conductivity of the fluid, Pr is the Prandtl number, $\mathrm{X}$ represents the position on the surface, and subscript $\mathrm{x}$ stands for local properties. The average free convection coefficient may be then obtained by integration along the surface, as in eqn (3):

$$
h=\frac{1}{A} \int h_{x} d A=\frac{1}{L} \int_{0}^{L} h_{x} d x
$$

Figure 4 shows the thermal circuit considered. Since there is no heat generation in the chocolate container, in the steady state the heat flux is constant from $\mathrm{T}_{1}$ (the internal wall of the chocolate container, facing the hot water flux) and $\mathrm{T}_{4}$ (the free convection condition under consideration). $\mathrm{T}_{1}$ is the average internal temperature. $T_{2}$ corresponds to the average chocolate temperature facing the exposed surface, and is called external temperature in this study. $T_{3}$ is the external surface of the stainless steel container. The thermal resistance between $\mathrm{T}_{2}$ and $\mathrm{T}_{3}$ was neglected, since the plate has just $1.5 \mathrm{~mm}$ of thickness and a thermal conductivity coefficient of $14.9 \mathrm{~W} /(\mathrm{m} . \mathrm{K})$ [6].

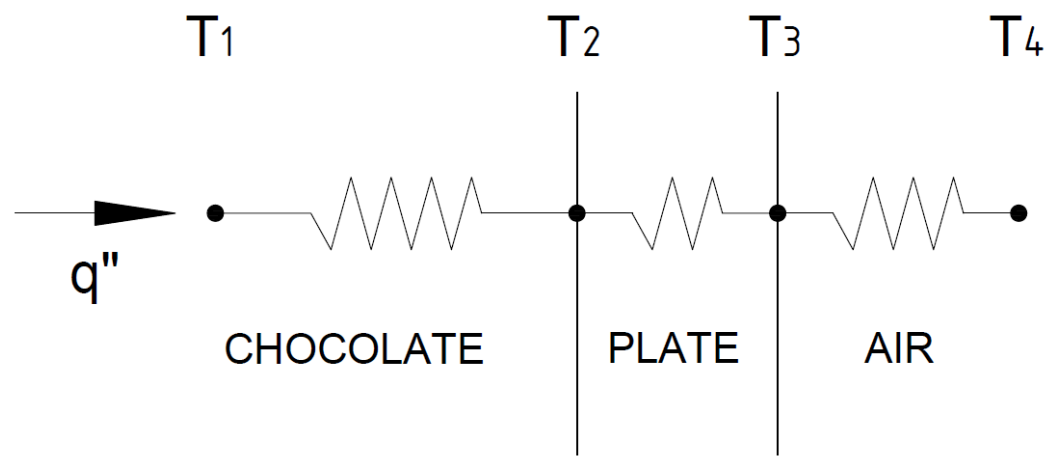

Figure 4: Thermal resistance circuit for heat flow. 
By applying the thermal resistance analogies, the heat flux (q") may be written as in eqn (4):

$$
q^{\prime \prime}=k \frac{d T}{d x}=h\left(T_{2}-T_{\infty}\right)
$$

and the thermal conductivity is calculated by applying eqn (5):

$$
k=\frac{h L\left(T_{2}-T_{\infty}\right)}{\left(T_{1}-T_{2}\right)}
$$

In eqns (4) and (5), $\mathrm{k}$ is the thermal conductivity of the chocolate, $\mathrm{L}$ is the thickness of the chocolate container $(\mathrm{m})$ and $\mathrm{h}$ is the global convection coefficient calculated by integrating the Nusselt correlation $\left(\mathrm{W} /\left(\mathrm{m}^{2} \cdot \mathrm{K}^{-1}\right)\right)$.

\section{Results}

The following figures represent the temperature measurements done for each chocolate formula and using different external conditions like free convection with air and melting ice.

Figure 5 corresponds to the free convection experiments with melting ice in front of the container to force a significant temperature gradient through the chocolate. The temperature of the chocolate at the external wall decreased significantly in a short time, because of melting ice. However, the system did not reach the steady state, owing to the latent heat of ice fusion. Therefore, it was not possible to determine how much heat was required to melt the ice, and how much heat was removed by water free convection. Then, the experiments with ice were substituted by air free convection.

On Figure 6 the results are shown with air free convection in contact with the external wall. In those experiments, ambient air temperature was $20^{\circ} \mathrm{C}$. After 60 minutes, the external temperature reached steady state, between $29^{\circ} \mathrm{C}$ and $35^{\circ} \mathrm{C}$, depending on the chocolate. The temperature gradient (internal temperature minus external temperature) was around $15^{\circ} \mathrm{C}$ in all cases.

Figure 7 shows the chocolate temperature measurements with an ambient air temperature of $30^{\circ} \mathrm{C}$ and the systems took 90 minutes to reach steady state. This is the optimal situation for an industrial plant, because of the thermal comfort for the people that work around the equipment. The thermal equilibrium point happened at a higher temperature, around $40^{\circ} \mathrm{C}$. The temperature gradient established in the chocolate container was around $15^{\circ} \mathrm{C}$.

To determine the thermal conductivity, conduction and free convection heat mechanisms were compared, by using eqn (5). Results are reported on Figure 8, for the different chocolate formulas.

Figure 8 shows a variation in thermal conductivity caused by both temperature and formulation. The results are in good agreement with the literature $[2,7]$, where $0.275 \mathrm{~W} /(\mathrm{m} . \mathrm{K})$ at $20.4^{\circ} \mathrm{C}$ and $0.261 \mathrm{~W} /(\mathrm{m} . \mathrm{K})$ at $33.9^{\circ} \mathrm{C}$ are reported. The results validate the method. 

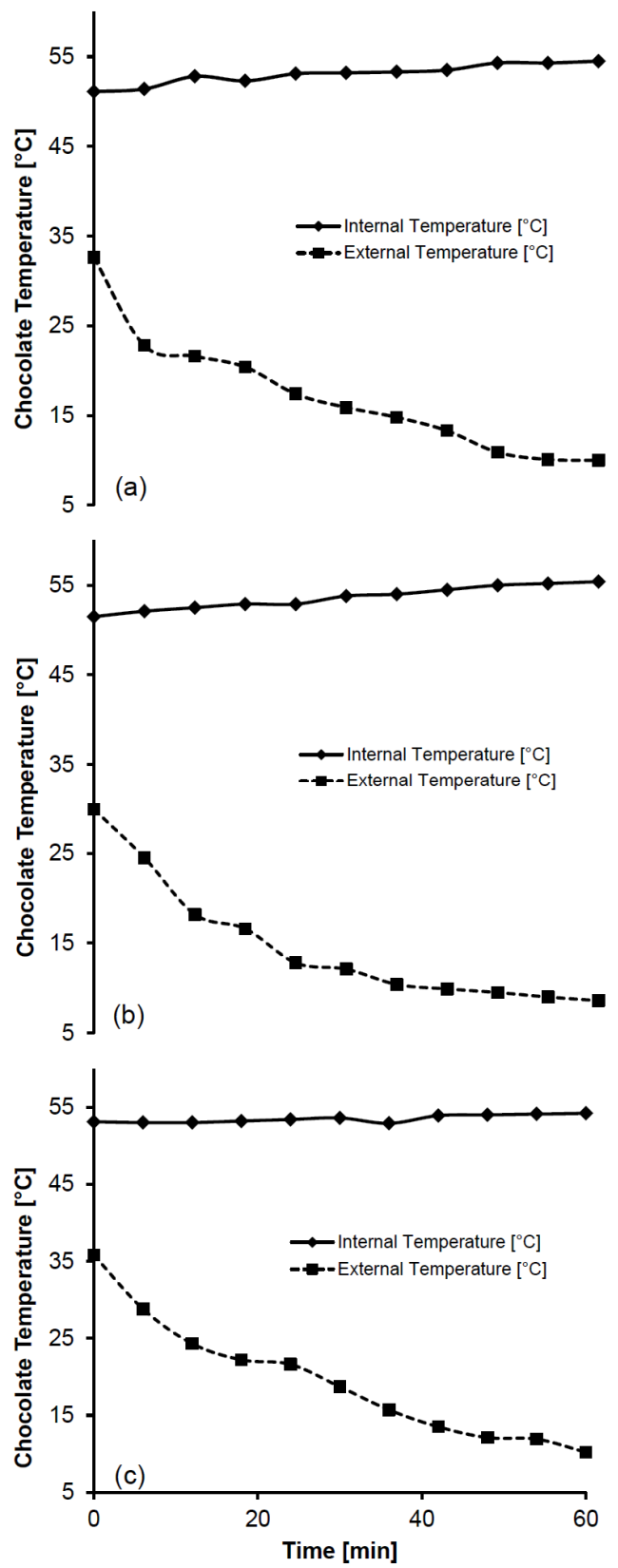

Figure 5: Differences between the chocolate temperature measurement at $20^{\circ} \mathrm{C}$ ambient temperature using free convection by melting ice for (a) milk chocolate, (b) semisweet chocolate and (c) white chocolate. 

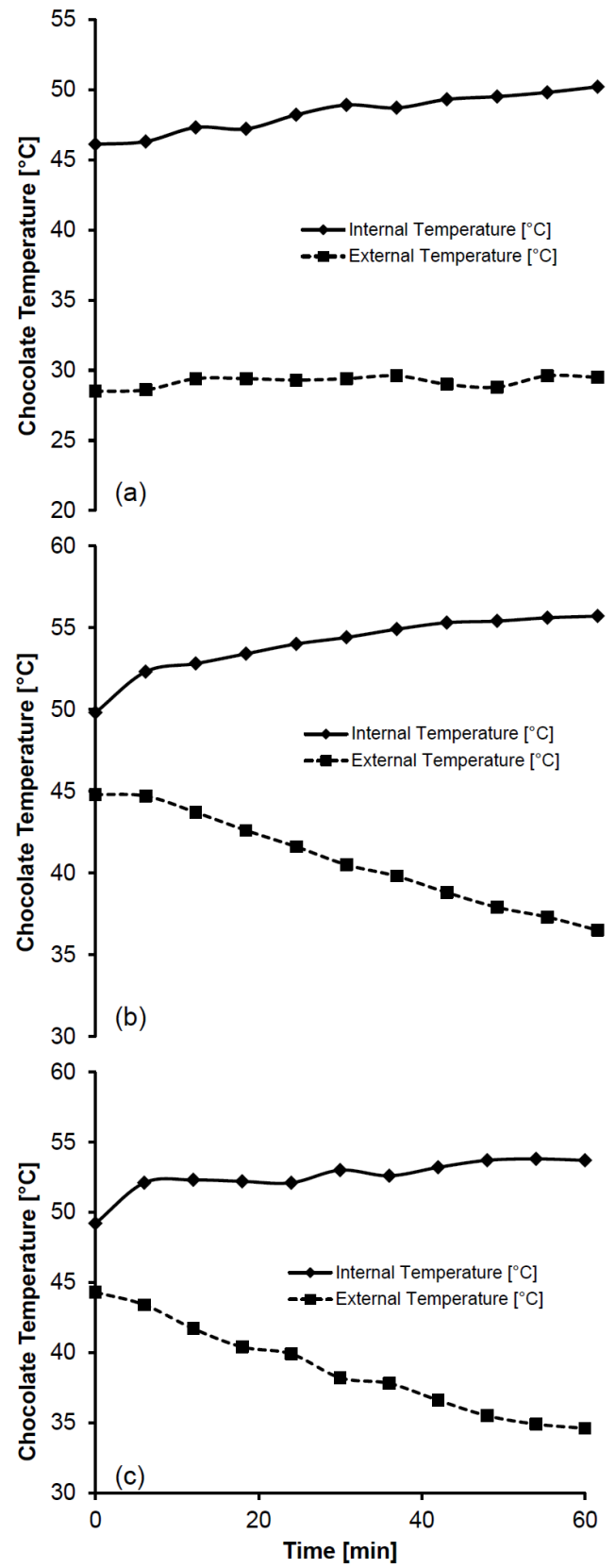

Figure 6: Differences between the chocolate temperature measurement at $20^{\circ} \mathrm{C}$ ambient temperature using free convection by air for (a) milk chocolate, (b) semisweet chocolate and (c) white chocolate. 

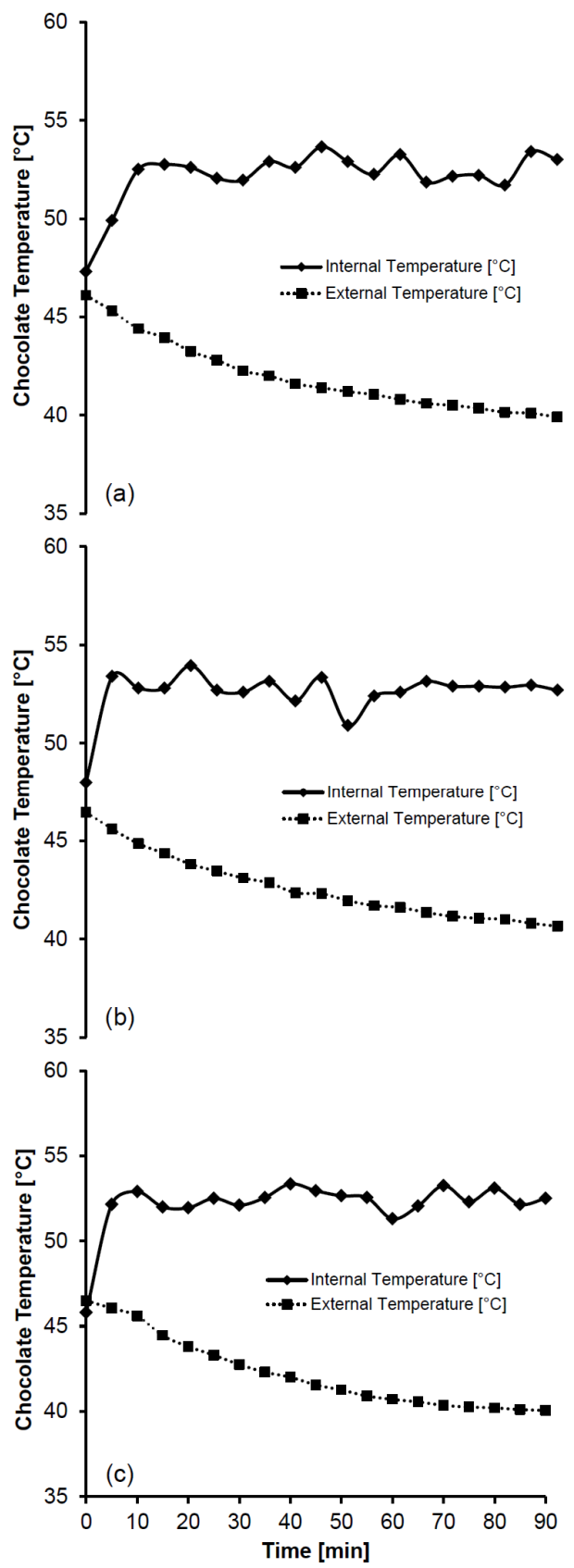

Figure 7: Differences between the chocolate temperature measurement at $30^{\circ} \mathrm{C}$ ambient temperature using free convection by air for (a) milk chocolate, (b) semisweet chocolate and (c) white chocolate. 


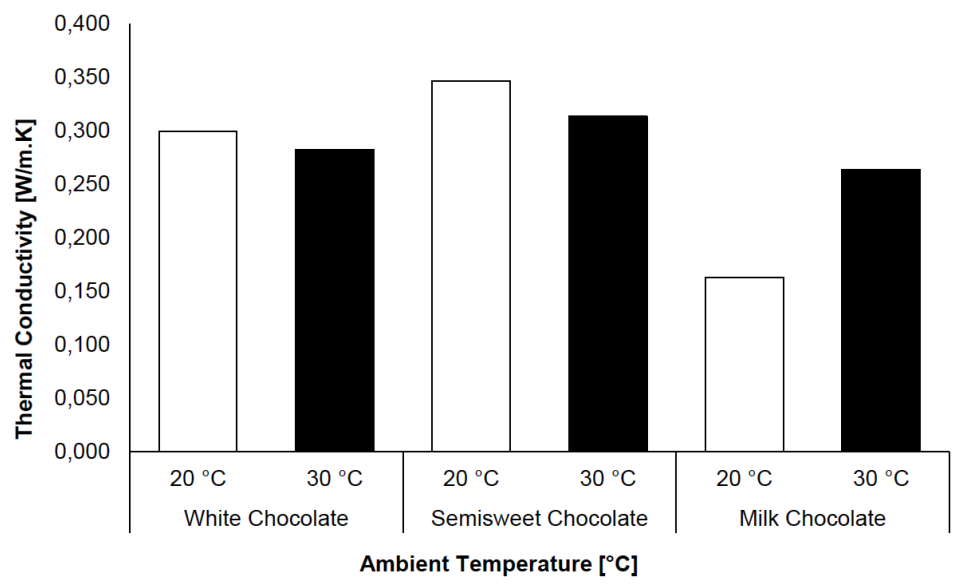

Figure 8: Variation of the thermal conductivity according the ambient temperature at $20^{\circ} \mathrm{C}$ and $30^{\circ} \mathrm{C}$.

\section{Conclusions}

A method to determine the thermal conductivity of melting chocolate based on thermal resistance analogies was proposed. The chocolate temperature gradient in the chocolate container was imposed by providing a heat flux and free convection conditions at the external surface. When the free convection was obtained by using melting ice, the temperatures did not reach steady state, owing to the latent heat of ice fusion. On the other hand, when air free convection was imposed, the results of thermal conductivity obtained, ranging from 0.150 $\mathrm{W} /(\mathrm{m} . \mathrm{K})^{-1}$ to $0.350 \mathrm{~W} /(\mathrm{m} . \mathrm{K})^{-1}$, were in agreement with the literature, with slight variations depending on the air temperature and on the chocolate formula.

The agreement with literature proves that the unit can be used to evaluate the thermal conductivity for a variety of formulas.

\section{References}

[1] Fernandes, V.A.; Müller, A.J.; Sandoval, A.J., Thermal, structural and rheological characteristics of dark chocolate with different compositions. J. Food Engineering, 116, 97-108, 2013.

[2] Le Révérend, B.J.D.; Smart, I.; Fryer, P.J.; Bakalis, S., Modelling the rapid cooling and casting of chocolate to predict phase behaviour, Chemical Engineering Science 66, 1077-1086, 2011.

[3] Manzocco, L.; Calligaris, S.; Camerin, M.; Pizzale, L.; Nicoli, M.C., Prediction of firmness and physical stability of low-fat chocolate spreads, J. Food Engineering, 126, 120-125, 2014. 
[4] Glicerina, V.; Balestra, F.; Rosa, M.D.; Romani, S. Rheological, textural and calorimetric modifications of dark chocolate during process, J. Food Engineering 119, 173-179, 2013.

[5] Singh, P. R.; Heldman, D. R. Introduction to food engineering. United States of America: AP Academic Press, 2001.

[6] Incropera, F. P. Dewitt, D. P. Fundamentals of heat and mass transfer. 5th ed. John Wiley \& Sons, 1992.

[7] Tewkesbury, H.; Stapley, A.G.F.; Fryer, P.J., Modelling temperature distributions in cooling chocolate moulds, Chemical Engineering Science $55,3123-3132,2000$. 